University of Wollongong

Research Online

Faculty of Engineering and Information

Faculty of Engineering and Information

Sciences - Papers: Part B

Sciences

2018

Integrating photovoltaic thermal collectors and thermal energy storage

systems using phase change materials with rotary desiccant cooling

systems

\author{
Haoshan Ren \\ University of Wollongong, hr681@uowmail.edu.au \\ Zhenjun Ma \\ University of Wollongong, zhenjun@uow.edu.au \\ Wenye Lin \\ University of Wollongong,wenye@uow.edu.au \\ Wenke Fan \\ University of Wollongong,wf303@uowmail.edu.au \\ Weihua Li \\ University of Wollongong, weihuali@uow.edu.au
}

Follow this and additional works at: https://ro.uow.edu.au/eispapers1

Part of the Engineering Commons, and the Science and Technology Studies Commons

Research Online is the open access institutional repository for the University of Wollongong. For further information contact the UOW Library: research-pubs@uow.edu.au 


\title{
Integrating photovoltaic thermal collectors and thermal energy storage systems using phase change materials with rotary desiccant cooling systems
}

\author{
Abstract \\ This paper presents a feasibility investigation of integrating a hybrid photovoltaic thermal collector-solar \\ air heater (PVT-SAH) and an air-based thermal energy storage (TES) system using phase change \\ materials (PCMs) with rotary desiccant cooling systems for residential applications. The PVT-SAH is used \\ to generate both electricity and thermal energy, while the TES unit is used to solve the mismatch between \\ energy demand for desiccant wheel regeneration and thermal energy generation from the PVT-SAH. A \\ near-optimal design of the proposed system is first identified using the response surface method. The \\ feasibility is then examined using three performance indicators, including Solar Thermal Contribution \\ (STC), Supply Air Temperature Unsatisfied (SATU) factor and Supply Air Humidity Ratio Unsatisfied \\ (SAHRU) factor. The results showed that the STC increased from $82.6 \%$ to $100.0 \%$ when the regeneration \\ temperature decreased from $70^{\circ} \mathrm{C}$ to $60^{\circ} \mathrm{C}$ under the simulation days. For the regeneration temperature \\ considered (i.e. $60^{\circ} \mathrm{C}, 65^{\circ} \mathrm{C}$ and $70^{\circ} \mathrm{C}$ ), the supply air temperature can always be satisfied while the \\ SAHRU factor decreased from $24.2 \%$ to $6.0 \%$ when the regeneration temperature increased from $60{ }^{\circ} \mathrm{C}$ to \\ $70^{\circ} \mathrm{C}$. The overall results illustrated that the PVT-SAH and PCM TES unit can be potentially used to \\ regenerate desiccant wheels if the system is appropriately designed.

\section{Disciplines} \\ Engineering | Science and Technology Studies

\section{Publication Details} \\ Ren, H., Ma, Z., Lin, W., Fan, W. \& Li, W. (2018). Integrating photovoltaic thermal collectors and thermal \\ energy storage systems using phase change materials with rotary desiccant cooling systems. \\ Sustainable Cities and Society, 36 131-143.
}




\section{Integrating photovoltaic thermal collectors and thermal energy storage} systems using phase change materials with rotary desiccant cooling systems

Abstract: This paper presents a feasibility investigation of integrating a hybrid photovoltaic thermal collector-solar air heater (PVT-SAH) and an air-based thermal energy storage (TES) system using phase change materials (PCMs) with rotary desiccant cooling systems for residential applications. The PVT-SAH is used to generate both electricity and thermal energy, while the TES unit is used to solve the mismatch between energy demand for desiccant wheel regeneration and thermal energy generation from the PVT-SAH. A near-optimal design of the proposed system is first identified using the response surface method. The feasibility is then examined using three performance indicators, including Solar Thermal Contribution (STC), Supply Air Temperature Unsatisfied (SATU) factor and Supply Air Humidity Ratio Unsatisfied (SAHRU) factor. The results showed that the STC increased from $82.6 \%$ to $100.0 \%$ when the regeneration temperature decreased from $70{ }^{\circ} \mathrm{C}$ to $60{ }^{\circ} \mathrm{C}$ under the simulation days. For the regeneration temperature considered (i.e. $60{ }^{\circ} \mathrm{C}, 65{ }^{\circ} \mathrm{C}$ and $70{ }^{\circ} \mathrm{C}$ ), the supply air temperature can always be satisfied while the SAHRU factor decreased from $24.2 \%$ to $6.0 \%$ when the regeneration temperature increased from $60{ }^{\circ} \mathrm{C}$ to $70{ }^{\circ} \mathrm{C}$. The overall results illustrated that the PVT-SAH and PCM TES unit can be potentially used to regenerate 
1 desiccant wheels if the system is appropriately designed.

2 Keywords: Photovoltaic thermal collector; Phase change materials; Desiccant wheel;

3 Regeneration; Feasibility study

\section{Nomenclature}

5 A area $\left(\mathrm{m}^{2}\right)$

$6 \quad A_{\text {fin }} \quad$ fin surface area $\left(\mathrm{m}^{2}\right)$

$7 \quad b \quad$ coefficient

$8 \quad C_{p} \quad$ specific heat $\left(\mathrm{J} \mathrm{kg}^{-1} \mathrm{~K}^{-1}\right)$

$9 \quad E \quad$ energy (J)

$10 h \quad$ enthalpy $\left(\mathrm{J} \mathrm{kg}^{-1}\right)$

$11 h_{c} \quad$ forced convection coefficient $\left(\mathrm{W} \mathrm{m}^{-2} \mathrm{~K}^{-1}\right)$

$12 h_{n c} \quad$ natural convection coefficient $\left(\mathrm{W} \mathrm{m}^{-2} \mathrm{~K}^{-1}\right)$

$13 h_{r} \quad$ radiation heat transfer coefficient $\left(\mathrm{W} \mathrm{m}^{-2} \mathrm{~K}^{-1}\right)$

$14 h_{w} \quad$ wind convection coefficient $\left(\mathrm{W} \mathrm{m}^{-2} \mathrm{~K}^{-1}\right)$

$15 \quad H_{\text {fin }} \quad$ fin height (m)

$16 \quad I_{t}$ global solar irradiation $\left(\mathrm{W} \mathrm{m}^{-2}\right)$

$17 k$ thermal conductivity $\left(\mathrm{W} \mathrm{m}^{-1} \mathrm{~K}^{-1}\right)$

$18 \dot{m} \quad$ mass flow rate $\left(\mathrm{kg} \mathrm{s}^{-1}\right)$

$19 M \quad$ mass per unit area $\left(\mathrm{kg} \mathrm{m}^{-2}\right)$

20 MRC moisture removal capacity $\left(\mathrm{kg} \mathrm{h}^{-1}\right)$

$21 q$ heat flux density $\left(\mathrm{W} \mathrm{m}^{-2}\right)$

$22 \quad R H \quad$ relative humidity 
1 STC solar thermal contribution

$2 t \quad$ time (s)

$3 \quad T \quad$ temperature $\left({ }^{\circ} \mathrm{C}\right)$

$4 \quad v \quad$ velocity $\left(\mathrm{m} \mathrm{s}^{-1}\right)$

$5 \quad W \quad$ water content of the desiccant material $\left(\mathrm{kg} \mathrm{kg}^{-1}\right)$

$6 \quad W_{d} \quad$ width (m)

$7 \quad x \quad$ independent variable

$8 \Delta x \quad$ length of a control volume (m)

$9 \quad y \quad$ objective response

$10 Y$ humidity ratio ( $\mathrm{kg} \mathrm{kg}^{-1}$ dry air)

11 Greek symbols

$12 \alpha$ absorptivity

$13 \delta \quad$ thickness (m)

$14 \quad \eta \quad$ dehumidification effectiveness

$15 \theta$ mass flow rate ratio of regeneration air to process air

$16 \rho \quad$ density $\left(\mathrm{kg} \mathrm{m}^{-3}\right)$

17 Subscripts

$18 \quad a \quad$ air

$19 a m b \quad$ ambient

20 ap absorber plate

$21 \quad b \quad$ before

$22 \quad b p \quad$ bottom plate 
1 eh electric heater

$2 g$ glass cover

3 in inlet

4 pro process

$5 \quad p v \quad$ PV plate

6 reg regeneration

7 SC $\quad$ solar contribution

8 Abbreviations

9 ANOVA Analysis of Variance

10 COP Coefficient of Performance

11 DCOP Dehumidification Coefficient of Performance

12 DSC Differential Scanning Calorimetry

13 IEC Indirect Evaporative Cooler

14 IWEC International Weather for Energy Calculations

15 PCM Phase Change Material

16 PV Photovoltaic

17 PVT Photovoltaic Thermal

18 RSM Response Surface Method

19 SAH Solar Air Heater

20 SAHRU Supply Air Humidity Ratio Unsatisfied

21 SATU Supply Air Temperature Unsatisfied

22 TES Thermal Energy Storage 


\section{Introduction}

Over the last two decades, rotary desiccant cooling systems have been considered as one of alternative approaches to replacing conventional vapor compression systems as such systems do not use chlorofluorocarbons and have the capability of independent temperature and humidity control (La, Dai, Li, Wang, \& Ge, 2010; Jani, Mishra, \& Sahoo, 2016a).

Compared to traditional vapour compression systems, rotary desiccant cooling systems are more energy efficient and environmentally friendly (La et al. 2010).

Various types of rotary desiccant cooling systems and their potentials to maintain acceptable indoor thermal comfort under different climatic conditions have been studied (Jani, Mishra, \& Sahoo, 2015; Jani et al. 2016a; Jani, Mishra, \& Sahoo, 2016b; Jani, Mishra, \& Sahoo, 2016c; Khalid, Mahmood, Asif, \& Muneer, 2009; Baniyounes, Liu, Rasul, \& Khan, 2013). For instance, White, Kohlenbach, and Bongs (2009) evaluated the performance of a $100 \%$ fresh air solar desiccant cooling system. It was found that the indoor thermal comfort could be maintained at or near the acceptable levels using the proposed system under the Melbourne and Sydney climatic conditions. Enteria et al. (2010) developed a solar cooling and heating system with double cross-flow heat exchangers. The experimental results indicated that the amount of cooling produced by the system was not proportional to the thermal energy supplied to the desiccant cooling system and the regeneration temperature of $65{ }^{\circ} \mathrm{C}$ was enough to support the dehumidification process. Baniyounes, Liu et al. (2013) investigated the performance of a solar assisted absorption cooling system and a solar assisted rotary desiccant cooling system for an institutional building. The simulation results showed that the desiccant cooling system achieved a higher solar fraction than the absorption cooling 
1 system. Baniyounes, Rasul, and Khan (2013) experimentally investigated the performance of

2 a solar desiccant cooling system. The results showed that the proposed system could achieve

$318 \%$ energy savings, in comparison to a conventional heating, ventilation and air-conditioning

4 system. Zeng, Li, Dai, and Xie (2014) numerically investigated the annual performance of a

5 solar hybrid one-rotor two-stage desiccant cooling and heating system under the weather

6 condition of Shanghai, China. The simulation results showed that about $60 \%$ of humidity load

7 could be handled by the proposed system and $40 \%$ of the heating demand in winter could be

8 covered by solar energy. Mei, Infield, Eicker, Loveday, and Fux (2006) investigated a solar

9 rotary desiccant cooling system, in which the regenerated air was first heated by a PV façade

10 and PV sheds in parallel and then further heated by solar air collectors. The simulation results

11 indicated that the average thermal COP of the desiccant cooling system in the summer period

12 was 0.518 and a regeneration temperature of about $70{ }^{\circ} \mathrm{C}$ can be provided by the proposed

13 PV-solar air heating system. A similar desiccant cooling system with air-based PVT and solar

14 air collectors connected in series to regenerate a desiccant wheel was studied by Beccali, 15 Finocchiaro, and Nocke (2009). The results showed that the majority (up to 90\%) of the 16 cooling demand of the case study office can be covered by the solar-assisted desiccant cooling 17 system. In the aforementioned studies, the heated air generated from solar systems was 18 directly used to regenerate rotary desiccant cooling systems. However, these systems cannot 19 satisfy building cooling demand during the nighttime.

20 Thermal energy storage (TES) using phase change materials (PCMs) can be used as an 21 alternative solution to solve the discrepancy between thermal energy demand and supply.

22 PCMs with the ability to provide high energy storage densities and the characteristics to store 
1 thermal energy at a relatively constant temperature have attracted increasing attention for

2 developing high-performance buildings (Ma, Lin, \& Sohel, 2016). For instance, Fiorentini,

3 Wall, Ma, Braslavski and Cooper (2017) presented an air-conditioning system, in which an

4 air-based PCM TES unit was used to regulate the thermal energy demand of a house and

5 thermal energy generation from the PVT collectors and a model predictive strategy was used

6 to control the operation of this system. A mathematical model for a PCM-air heat exchanger

7 was developed by Dolado, Lazaro, Marin, and Zalba (2011) to examine the PCM melting and

8 solidification characteristics. The results indicated that increasing the rugosity of PCM

9 encapsulation can significantly improve the convective heat transfer between the air and the

10 PCM. Lin, Ma, Sohel, and Cooper (2014) developed a PVT-PCM integrated ceiling

11 ventilation system for space heating and cooling. It was found that this system can effectively

12 improve the indoor thermal comfort of passive buildings without using air-conditioning

13 systems in winter conditions. Charvát, Klimeš, and Ostrý (2014) experimentally and

14 numerically investigated a PCM TES unit for solar air systems. It was shown that the PCM in

15 the first row of the panels was fully melted in less than one hour while it took several hours to

16 melt the PCM in the last row of the panels. The results from the above studies demonstrated

17 that PCMs could play an essential role in effective building thermal energy management.

18 This study presents a feasibility study of integrating a hybrid photovoltaic thermal

19 collector-solar air heater (PVT-SAH) and a PCM TES unit with a rotary desiccant cooling

20 system. The regeneration temperatures commonly used in rotary desiccant cooling systems

21 are first briefly reviewed. The feasibility study is then performed based on three regeneration

22 temperatures and three performance indicators including Solar Thermal Contribution (STC), 
1 Supply Air Temperature Unsatisfied (SATU) factor and Supply Air Humidity Ratio

2 Unsatisfied (SAHRU) factor. The novelty of this present work is to use a PCM TES unit to

3 solve the discrepancy between the thermal energy demand and the thermal energy generation

4 of PVT-SAH systems to maximize the solar thermal contribution to the regeneration of rotary

5 desiccant cooling systems.

\section{Overview of regeneration temperatures used in rotary desiccant cooling systems}

In a rotary desiccant cooling system, the cooling process is achieved by removing the moisture from the process air using a desiccant wheel and reducing the temperature of the process air using evaporative cooling or other cooling technologies.

The desiccant wheel is therefore one of the key components in a rotary desiccant cooling system. A desiccant wheel generally consists of a large number of air channels whose walls coated or impregnated with desiccant materials (Ge, Ziegler, \& Wang, 2010). The cross-section of a desiccant wheel can be divided into the process side and the regeneration side. The moisture of the process air is adsorbed by the desiccant material when it passes through the process side of the desiccant wheel and at the same time, the regeneration air flows through the regeneration side where the desiccant material is heated and dehumidified.

The regeneration air temperature (i.e. regeneration temperature) is one of the significant variables influencing the performance of a rotary desiccant cooling system. In general, the desiccant materials can capture more moisture from the process air if the materials are more deeply dried under a higher regeneration temperature. Moisture removal capacity (MRC), 
1 desiccant cooling system (Angrisani, Minichiello, Roselli, \& Sasso, 2012), increases with the

2 increase of the regeneration temperature as the desorption process in the desiccant matrix is

3 endothermic (Sheng et al., 2014). A study showed that the dehumidification effectiveness ( $\eta$ ),

4 which represents the ratio between the real and the ideal dehumidification capability of a

5 desiccant wheel (Angrisani et al., 2012), increased from 0.54 to 0.58 when the regeneration

6 temperature increased from $60{ }^{\circ} \mathrm{C}$ to $90{ }^{\circ} \mathrm{C}$ (Eicker et al., 2012). The study from Ali, Vukovic,

7 Sahir, \& Basciotti (2013) showed that the increase rate of MRC of a rotary desiccant cooling

8 system decreased with increasing regeneration temperature. For a rotary desiccant cooling

9 system, the maximum dehumidification coefficient of performance (DCOP), which is the ratio

10 of the latent heat contained in the adsorbed moisture to the thermal energy required to produce

11 the high-temperature regeneration air, can be obtained at a certain regeneration temperature

12 (Ge et al., 2010). If the regeneration temperature is beyond this value, the energy cost required

13 to produce a higher temperature of the regeneration air will be higher than the benefit resulted

14 from the increased moisture removal. For desiccant wheels using composite desiccants, the

15 maximum DCOP can be generally obtained when the regeneration temperature was around 85

$16{ }^{\circ} \mathrm{C}$ (Ge et al., 2010). Therefore, there is an optimal regeneration temperature which can

17 maximize the overall performance of a rotary desiccant cooling system.

18 Table 1 summarizes the regeneration temperatures used in the rotary desiccant cooling

19 systems studied. It can be seen that the regeneration temperature studied varied between $35{ }^{\circ} \mathrm{C}$

20 and $120{ }^{\circ} \mathrm{C}$. Several studies showed that the dehumidification efficiency of rotary desiccant

21 cooling systems can be generally acceptable when the regeneration temperature was in the

22 range of $60-70{ }^{\circ} \mathrm{C}$. 


\section{System description and research method}

\subsection{System description}

A schematic of a rotary desiccant cooling system with a hybrid PVT-SAH and a PCM TES unit is illustrated in Fig. 1. In this system, the hybrid PVT-SAH, in which the PVT collector and the SAH are connected in series, was used for both electricity and low-grade thermal energy generation. The thermal energy collected from the PVT-SAH can be used to drive the desiccant wheel regeneration in cooling conditions or for space heating in heating conditions. The electricity generated by the PV plate can be used to power the electric heater and fans used in the system and the excessive electricity can be stored in a battery or exported to the grid. The use of such a hybrid system is to achieve a relatively high air temperature while still maintaining necessary electricity generation and reducing the system operation cost (Beccali, et al., 2009). An air-based PCM TES unit (see Fig. 2) with a similar configuration as that reported by Charvát et al. (2014) was used to regulate the discrepancy between the thermal energy generated from the PVT-SAH and the thermal energy demand for the desiccant wheel regeneration. The PCM TES unit consisted of a number of PCM layers arranged in parallel and each PCM layer consisted of multiple PCM panels. A desiccant wheel, a heat recovery unit and an indirect evaporative cooler (IEC) were used to condition the process air.

This proposed system can be used for both daytime and nighttime cooling dependent on the building cooling demand. It can also be used for winter space heating. Table 2 describes the main potential operation modes.

In the process air side, the return air from the indoor space is first mixed with the fresh air 
1 and then used as the process air in order to improve the system efficiency. The process air is

2 first dehumidified by the desiccant wheel and then cooled by a heat recovery unit and an IEC.

3 Under the operation mode IV, the regeneration air is first processed by the heat recovery unit

4 and then by the PCM TES unit while under the operation modes I and II, the outlet air from

5 the heat recovery unit is discharged to ambient directly. It is worthwhile to note that a bypass

6 was designed for the PCM TES unit in order to avoid the overheating of the regeneration air.

$7 \quad 3.2$. Research method

The overall procedure used for the feasibility study of the proposed system is illustrated in Fig. 3, which consisted of three steps including setup of the test, performance evaluation

10 and optimization, and the feasibility analysis. In the first step, a virtual simulation system of

11 the proposed system was developed using TRNSYS (Klein, 2010), which will be introduced in Section 4, and the key performance indicators to be used for performance evaluation were determined. In the second step, the key factors governing the performance of the PVT-SAH and PCM TES unit were first determined based on the results from the previous studies (Dolado et al., 2011; Duffie, \& Beckman, 2013; Fan, Kokogiannakis, Ma, \& Cooper, 2017). The simulation cases were then designed and executed using the response surface method. Based on the simulation data, the response surface models were developed and the optimal combination of the factors was determined. In the third step, a confirmation test with the optimal combination of the factors identified was carried out and the feasibility of the proposed system for desiccant wheel regeneration was analysed.

\subsubsection{Selection of performance indicators}


1 Supply Air Temperature Unsatisfied (SATU) factor and Supply Air Humidity Ratio

2 Unsatisfied (SAHRU) factor, were used to evaluate the performance of the proposed system

3 under dynamic working conditions. STC is defined as the ratio of the total amount of thermal

4 energy that can be provided by the hybrid PVT-SAH and PCM TES unit for desiccant wheel

5 regeneration to the total thermal energy needed for desiccant wheel regeneration under a

6 required regeneration temperature and a time period of concern, as expressed in Eq. (1)

7 (Enteria et al., 2011). The thermal energy supplied by the PVT-SAH and PCM TES unit is

8 determined by Eq. (2), in which the air temperature before the electric heater $\left(T_{b, e h, a}\right)$ can be

9 the temperature of the outlet air from the PVT-SAH or from the PCM TES unit dependent on

10 which operation mode was used for desiccant wheel regeneration. The power consumption of

11 the auxiliary electric heater is determined by Eq. (3) if the outlet air temperature from the

PVT-SAH or PCM TES unit was less than the required regeneration temperature. The regeneration air flow rate $\left(\dot{m}_{r e g, a}\right)$ was calculated using Eq. (4) based on the configuration of

14 the desiccant wheel.

$$
\mathrm{STC}=\frac{E_{S c}}{E_{s c}+E_{e h}}
$$

$$
E_{s c}=\int_{t_{1}}^{t_{2}}\left[\dot{m}_{r e g, a, i} C_{p, a}\left(T_{b, e h, a, i}-T_{a, i n, i}\right)\right] d t
$$

$7 \quad E_{e h}=\int_{t_{1}}^{t_{2}}\left[\dot{m}_{r e g, a, i} C_{p, a}\left(T_{r e g, a}-T_{b, e h, a, i}\right)\right] d t$

$8 \dot{m}_{r e g, a}=\theta \dot{m}_{p r o, a}$

19 where $E$ is the thermal energy, $\dot{m}$ is the mass flow rate, $T$ is the temperature, $C_{p}$ is the 20 specific heat, $t$ is the time, $\theta$ is the ratio of the mass flow rate of the regeneration air to that of 21 the process air, $t_{1}$ and $t_{2}$ are the start time and end time respectively, and the subscripts $a, b$, in, 22 pro, reg, sc, and eh indicate air, before, inlet, process, regeneration, solar contribution and 
1 electric heater, respectively. It is noted that $T_{a, i n}$ in Eq. (2) represents the temperature of the

2 ambient air to the hybrid PVT-SAH system when the desiccant wheel is directly regenerated

3 by the air supplied by the PVT-SAH (operation modes I and II). Otherwise, it represents the

4 inlet air temperature of the PCM TES unit if the system is operated under the operation mode

5 IV.

6 SATU factor and SAHRU factor were used to evaluate the performance of the rotary

7 desiccant cooling system under different regeneration temperatures. SATU factor was defined

8 as the ratio of the accumulated time that the supply air temperature is above the required

9 set-point to the total time of the desiccant cooling system in operation. Similarly, SAHRU

10 factor was defined as the ratio of the accumulated time that the supply air humidity ratio is

11 above the required set-point to the total time of the desiccant cooling system in operation.

\subsubsection{Performance investigation and optimization using response surface method}

In this study, a range of simulation exercises was designed and executed using the response surface method (RSM) to determine the near-optimal values of the main parameters of the hybrid PVT-SAH and PCM TES unit. The RSM is a set of mathematical and statistical techniques to optimize a response of interest which is influenced by a number of variables (Montgomery, 2008). As the primary focus of this study was to examine the feasibility of using the hybrid PVT-SAH and PCM TES unit to regenerate desiccant wheels, the STC was therefore selected as the response of the hybrid PVT-SAH and PCM TES unit. The SATU factor and SAHRU factor were only used to evaluate the performance of the rotary desiccant cooling system and were not considered in the RSM. The STC was investigated with three

22 levels $(-1,0,1)$ for each main parameter and the Face Centered Central Composite Design 
1 (Montgomery, 2008; Subasi, Sahin, \& Kaymaz, 2016) was used for the simulation design.

2 Based on the simulation results, a response surface model was generated through the stepwise

3 regression method, which was then used to predict the response of STC based on the

4 independent variables under various conditions. The general form of the response surface

5 model is presented in Eq. (5) (Wang, Lan, \& Li, 2014).

$$
y=b_{0}+\sum_{i=1}^{j} b_{i} x_{i}+\sum_{i=1}^{k} b_{i i} x_{i}^{2}+\sum_{i}^{i<j} \sum_{j} b_{i j} x_{i} x_{j}
$$

where $y$ is the predicted response, $x_{i}$ and $x_{j}$ are the independent variables, and $b_{0}, b_{i}, b_{i i}$, and $b_{i j}$ are the coefficients.

Analysis of variance (ANOVA) was used to evaluate the fitness of the model. The response surfaces were generated to visualize the individual and interactive effects of the main parameters on the response. The optimal combination of the main parameters to maximize the response (i.e. STC) was then determined. The RSM process was implemented using the trial version of Design Expert (Design Expert, 2010).

The PCM type, the length of the PCM TES unit, the size of the air gap between the glass cover and the PV plate/absorber plate in the PVT-SAH, and the air flow rate of the PVT-SAH, were considered as the major parameters in this study based on the following considerations. The PCM melting temperature and thermophysical properties will directly influence the amount of thermal energy that can be charged into the TES unit. The length of the PCM TES unit was used to control the total amount of the PCM used and therefore the storage capacity of the TES unit. The air flow rate of PVT-SAH influences its heat transfer performance and outlet air temperature. The air gap between the PV plate/absorber plate and the glass cover 
1 the air flow rate of the TES unit during the charging process was the same as that of the

2 PVT-SAH while that during the discharging process was determined based on the building

3 cooling demand.

4

\section{System modelling}

\subsection{Hybrid PVT-SAH}

The hybrid PVT-SAH system considered in this study is shown in Fig. 4, which consisted of a glass cover, a PV plate, an absorber plate, a bottom plate, and a number of fins. The fins were deployed between the bottom plate and absorber plate along the air flow direction to enhance the heat transfer performance. A dynamic model developed in a previous study (Fan et al., 2017) was used to simulate the performance of the hybrid PVT-SAH system. In this model, the PVT-SAH was first discretized into multiple control volumes along the air flow direction, and the PVT collector was further divided into 6 nodes perpendicular to the flow direction, including the glass cover, PV plate, absorber plate, fins, fluid air, and the bottom plate, while the SAH was divided into 5 nodes perpendicular to the flow direction by excluding the node for the PV plate. The key governing equation of the glass cover node in the PVT section is described in Eq. (6). The governing equations of the PV plate, the solar absorber plate, the fins, and the bottom plate can be described using the same way. The governing equation for the air flowing through the air channel is given by Eq. (7).

$$
A C_{p, g} M_{g} \frac{\partial T_{g, i}}{\partial t}=\alpha_{g} I_{t} A+h_{n c} A\left(T_{p v, i}-T_{g, i}\right)+h_{r, p v-g} A\left(T_{p v, i}-T_{g, i}\right)+h_{w} A\left(T_{a m b}-\right.
$$

$$
\left.T_{g, i}\right)+h_{r, g-s k y} A\left(T_{s k y}-T_{g, i}\right)
$$

$$
\begin{aligned}
& \quad C_{p, a} \rho_{a} \Delta x\left(W_{d} H_{f i n}\right) \frac{\partial T_{a, i}}{\partial t}+C_{p, a} \dot{m}_{a} \Delta x \frac{\partial T_{a, i}}{\partial x}=h_{c, a p-a} A\left(T_{a p, i}-T_{a, i}\right)+h_{c, b p-a} A\left(T_{b p, i}-\right. \\
& \left.T_{a, i}\right)+2 h_{c, f i n-a} A_{f i n}\left(T_{f i n, i}-T_{a, i}\right)
\end{aligned}
$$


1 where $A$ is the area, $M$ is the mass per unit area, $\alpha$ is the absorptivity, $I_{t}$ is the global solar

2 irradiation, $h_{n c}$ is the natural convection coefficient, $h_{r}$ is the radiation heat transfer coefficient,

$3 h_{w}$ is the wind convection coefficient, $\rho$ is the density, $W_{d}$ is the PVT-SAH width, $\Delta x$ is the

4 length of the control volume, $H_{\text {fin }}$ is the fin height, $h_{c}$ is the forced convection coefficient, $A_{\text {fin }}$

5 is the surface area of fins for a control volume in contact with flowing air, and the subscripts

$6 a m b, g, p v, a p$, and $b p$ indicate ambient, glass cover, PV plate, absorber plate and bottom plate,

7 respectively.

Similarly, the governing equations for each node of the SAH can be developed. By employing the Crank-Nicolson scheme, the above equations were discretized and solved.

10 More details of this model can be found in Fan et al. (2017).

\subsection{PCM TES unit}

A mathematical model for the PCM TES unit, which considered the hysteresis phenomenon but did not consider the supercooling during the phase change process, was developed using the enthalpy method based on the three main assumptions: a) the conduction heat transfer within the PCM panel is one-dimensional and perpendicular to the air flow direction; b) there is no natural convection in the air within the TES unit and; c) the convective heat transfer within the liquid PCM is negligible.

The schematic of the nodes in modelling the PCM TES unit is illustrated in Fig. 5. The PCM TES unit was divided into multiple sections containing both air nodes and PCM panels along the air flow direction. The governing equations for the energy balance of PCM panels and air flow are expressed in Eqs. (8) and (9), respectively.

The Gnielinski equation was used to calculate the Nusselt number of the turbulent flow 
1 (Lin et al., 2014; Gnielinski, 1976), and the Nusselt number of the laminar flow was

2 determined based on the aspect ratio of air channels (Bergman, Incropera, DeWitt, \& Lavine,

3 2011). The governing equations were solved based on the enthalpy-temperature relationship

4 of the PCM, which can be obtained from the Differential Scanning Calorimetry (DSC) test or

5 from the data sheets provided by manufacturers.

$$
\begin{aligned}
& \rho_{P C M} \frac{\partial h_{P C M}}{\partial t}=k_{P C M} \frac{\partial^{2} T_{P C M}}{\partial y^{2}} \\
& \rho_{a} C_{p, a}\left(\frac{\partial T_{a}}{\partial t}+v_{a} \frac{\partial T_{a}}{\partial x}\right)=\frac{q_{u p}+q_{d o w n}}{\delta_{a}}
\end{aligned}
$$

where $h$ is the enthalpy, $k$ is the thermal conductivity, $v$ is the velocity, $q$ is the heat flux density, and $\delta$ is the thickness.

\subsection{Rotary desiccant cooling system}

The model of the rotary desiccant cooling system consisted of a heat recovery unit, an IEC, and a desiccant wheel. The heat recovery unit was modelled using TRNSYS component Type 760, in which a constant heat transfer effectiveness was assumed. The IEC was modelled using Type 757 with a constant effectiveness and without considering the water consumption. In this model, the outlet air condition from the IEC was determined based on the assumption that the secondary air stream process is a constant wet-bulb temperature process. The gas side and solid side resistance model for the desiccant wheel developed by Ge et al. (2010) was used in this study. The regular density silica gel was used as the desiccant material and the equilibrium relative humidity $(R H)$ on its surface was described by Eq. (10) (Pesaran, \& Mills, 1987).

$$
R H=0.0078-0.05759 W+24.16554 W^{2}-124.478 W^{3}+204.226 W^{4}
$$

where $W$ is the water content of the desiccant material. 


\section{Results and discussion}

\subsection{Validation of the PCM TES unit model}

The effectiveness of the PCM TES unit model was validated using the experimental data presented by Lopez, Kuznik, Baillis, and Virgone (2013), in which the inlet and outlet temperatures of the PCM TES unit were measured using type-K thermocouples with an accuracy of $\pm 0.4{ }^{\circ} \mathrm{C}$. The model developed was modified to have the same configuration as that of the experimental setup used by Lopez et al. (2013) through reducing the number of the air channels and assuming that the TES unit was well-insulated.

A comparison of the model simulation results with the experimental data reported by Lopez et al. (2013) under the air flow rate of $240 \mathrm{~m}^{3} \mathrm{~h}^{-1}$ is presented in Fig. 6. The simulated outlet air temperature from the PCM TES unit under both charging and discharging processes generally matched well with that of the experimental data probably due to the consideration of the hysteresis phenomenon during the phase change process, indicating that the model developed can provide an acceptable estimation.

\subsection{Setup of the simulation tests}

In this study, the proposed system was assumed to be used to condition a Solar Decathlon (SD) house. The house was divided into two thermal zones, including the living space of 43.0 $\mathrm{m}^{2}$ and the sleeping space of $23.0 \mathrm{~m}^{2}$. More details of the SD house can be found in Fiorentini (2016). The simulation study was carried out based on the working days. The house was assumed to be occupied with two residents and the schedule of the occupant activities is described in Table 3. It was assumed that the hybrid PVT-SAH was installed on the north roof of the house with a total area of $24 \mathrm{~m}^{2}$ and a roof slope of $18.4^{\circ}$. It is worthwhile to note that a 
1 larger area of PVT-SAH could bring more benefits. The performance of the proposed system

2 was evaluated under the operation modes III and IV as described in Table 2. It is worthwhile

3 to note that the system should be re-designed if it is primarily operated under the other

4 operation modes or there is a cooling demand during both daytime and nighttime.

Five consecutive summer days under Brisbane (Australia) weather conditions with

6 relatively higher temperatures and humidity ratios were selected to investigate the feasibility

7 of using the hybrid PVT-SAH and PCM TES unit for desiccant wheel regeneration as

8 Brisbane has reasonably abundant solar radiation and the humidity ratio is relatively high. The

9 weather data used in the simulation were the International Weather for Energy Calculations

10 (IWEC) data. Fig. 7 shows the ambient air temperature, humidity ratio, and total horizontal

11 solar radiation over the selected summer days in Brisbane.

The SD house model developed using DesignBuilder (DesignBuilder, 2017) in a previous study (Fiorentini, 2016) was used to simulate the cooling demand of the house during the

14 simulation days. The required supply air flow rate and the process air flow rate were then 15 determined based on the flow ratio between the primary and secondary air of the IEC. The regeneration air flow rate was determined using Eq. (4). The regeneration air was assumed to be heated from the ambient air temperature to a required regeneration temperature using the heat recovery unit, the PCM TES unit and the axillary electric heater during the nighttime.

Three scenarios with different regeneration temperatures of $60{ }^{\circ} \mathrm{C}, 65^{\circ} \mathrm{C}$, and $70{ }^{\circ} \mathrm{C}$ were used to evaluate the effect of the regeneration temperature on the performance of the proposed system in terms of the three performance indicators used. The simulation plans were designed for each scenario using the RSM. The levels of the four main parameters used in each 
scenario are specified in Table 4. The PCM type was considered as a categorical variable while the length of the PCM TES unit, the air gap of the PVT-SAH and the air flow rate were regarded as continuous variables. In principle, the levels of the PCM types should be different

4 for different regeneration temperatures. However, the same PCM types were used for 5 Scenarios $\mathrm{A}$ and $\mathrm{C}$ in this study mainly based on the consideration of the outlet air temperature of the PVT-SAH. The levels of the other parameters were considered as the same

7 for the three different scenarios. The thermophysical properties of the PCMs used are 8 summarized in Table 5 and an example of the enthalpy-temperature relationship of the 9 RT70HC is presented in Fig. 8. During the simulation, the initial temperature of the PCM in the TES unit was set as $50{ }^{\circ} \mathrm{C}$ to ensure that there was no latent thermal energy stored in the

11 PCM. The range of the size of the air gap between the glass cover and the PV plate/absorber 12 plate was determined based on the results of a previous study (Duffie et al., 2013). The range 13 of the air flow rate was selected in order to obtain a reasonably high outlet air temperature 14 from the PVT-SAH system. The length of the PCM TES unit was roughly determined based 15 on the house cooling demand and the average thermal COP (i.e. 0.518) of a rotary desiccant cooling system reported in a previous study (Mei et al., 2006). system used in this study are summarized in Table 6. To avoid a large pressure drop in the PCM TES unit and improve the convective heat transfer between the air flow and the PCM panel, the size of the air channels in the PCM TES unit was set as $10 \mathrm{~mm}$ based on the value recommended in a previous study (Dolado et al., 2011). The width of the TES unit was set as the same as the width of the PCM panel used (Rubitherm GmbH, 2016). The number of PCM 
1 layers was calculated based on the height of the TES unit which was set as $0.6 \mathrm{~m}$ assuming

2 that the unit will be placed under the suspended floor of the house. The channel depth of the

3 PVT-SAH was set as $25 \mathrm{~mm}$ based on the result from a previous study (Fan et al., 2017). The

4 ratio of the length of the PVT to that of the PVT-SAH was determined as 0.6 to ensure an

5 acceptable amount of electricity generation and also to achieve a relatively high outlet air

6 temperature from the PVT-SAH for desiccant wheel regeneration. The ratio of the

7 regeneration side area to that of the process side and the ratio of the regeneration air flow rate

8 to that of the process air were set as $1: 1$. The resulted simulation design for the scenario $\mathrm{A}$ is

9 summarized in Table 7 and the simulation designs for Scenarios B and C were similar to that

10 of Scenario A and were therefore not provided.

\subsection{Results from the performance simulation}

Table 7 summarizes the solar thermal contribution (STC) for all simulation exercises

designed for Scenario A when the regeneration temperature was $65{ }^{\circ} \mathrm{C}$. It can be seen that the

STC was in the ranges of 57.9-93.0\%, 52.2-95.7\% and 33.3-91.4\% when the PCMs of RT60,

RT65 and RT70HC were used.

A response surface model was then generated for each PCM type under the regeneration temperature of $65{ }^{\circ} \mathrm{C}$ based on the simulation results. Through the step-wise regression, the general response surface model for three PCMs determined is expressed in Eq. (11) and the coefficients used are summarized in Table 8.

$$
\mathrm{STC}=b_{0}+b_{1} x_{1}+b_{2} x_{2}+b_{3} x_{2}+b_{11} x_{1}^{2}+b_{22} x_{2}^{2}+b_{12} x_{1} x_{3}
$$

where $x_{1}, x_{2}$, and $x_{3}$ stand for the length, air gap, and air flow rate, respectively.

Fig. 9 a-c) present the variation in STC when changing the PCM TES length and the air 
1 gap between the glass cover and PV plate/absorber plate with different PCM types under the

2 air flow rate of $500 \mathrm{~kg} \mathrm{~h}^{-1}$ and the regeneration temperature of $65{ }^{\circ} \mathrm{C}$ while Fig. 9d) presents

3 the variation in STC with the change of the PCM TES length and air flow rate while keeping

4 the air gap of $16.0 \mathrm{~mm}$, PCM type of RT65, and regeneration temperature of $65{ }^{\circ} \mathrm{C}$. It can be

5 observed that the STC increased with the increase of PCM TES length under the same PCM

6 type and the air gap. The STC first increased and then decreased with increasing air gap under

7 the same PCM type and the PCM TES length. The optimal value of the air gap which can

8 maximize the STC was around 14.0-18.0 mm for different types of PCMs considered. The

9 highest STC under the flow rate of $500 \mathrm{~kg} \mathrm{~h}^{-1}$ was achieved when using RT65 among the

10 three PCMs tested. From Fig. 9d), it can be seen that the STC increased with the decrease of

11 the flow rate under a given PCM TES unit length, which was resulted from the increase in the

12 outlet air temperature of the PVT-SAH. Therefore, a relatively small charging air flow rate

13 was suggested in this proposed system.

14 Based on the response surface model, the optimal combination of the parameters to 15 maximize the STC of the hybrid PVT-SAH and PCM TES unit with the regeneration 16 temperature of $65{ }^{\circ} \mathrm{C}$ was determined and the results are presented in Table 9. The predicted 17 STC was $95.2 \%$ and the result from the confirmation test was $96.5 \%$ with a relative error of

18 1.3\%. Similar procedures were also carried out for Scenarios B and C to generate the response

19 surface models and the similar trends of STC as those of Scenario A were also observed. The

20 optimal designs identified for Scenario B and C are also summarized in Table 9 while the

21 detailed results were not provided in order to save the page size. It is worthwhile to note that

22 due to the prediction error of the response surface model, the STC predicted under some 
conditions were slightly higher than $100 \%$. However, in principle, this is not possible. From

2 Table 9, it is interesting to note that RT65 was selected as the optimal PCM for the three

3 different scenarios with different regeneration temperatures. This was mainly due to the

4 impact of the outlet air temperature from the PVT-SAH. It should be noted that the

5 near-optimal designs identified based on the five selected summer days might not be the

6 near-optimal solutions if the optimization was carried out based on the whole cooling season.

7 The simulation results based on the optimal values identified (i.e. Table 9) for Scenario A

8 are presented in Fig. 10. It can be seen that the supply air temperature and humidity ratio can

9 be generally controlled below $20{ }^{\circ} \mathrm{C}$ and $0.008 \mathrm{~kg} \mathrm{~kg}^{-1}$ dry air, respectively. During the

10 majority of the test period, the heat from the hybrid PVT-SAH and the PCM TES unit can

11 satisfy the heating demand for desiccant wheel regeneration when the regeneration 12 temperature was $65^{\circ} \mathrm{C}$.

13 The supply air conditions of the rotary desiccant cooling system under the regeneration

14 temperatures of $60{ }^{\circ} \mathrm{C}, 65{ }^{\circ} \mathrm{C}$, and $70{ }^{\circ} \mathrm{C}$ and under the optimal values identified (i.e. Table 9)

15 over the selected summer days are presented in Fig. 11. It can be seen that the humidity ratio

16 decreased with the increase of the regeneration temperature, indicating that the moisture

17 removal capacity of the desiccant wheel increased with the increase of the regeneration

18 temperature. During the simulation period, the supply air temperature was always maintained

19 lower than the desired condition (i.e. $20{ }^{\circ} \mathrm{C}$ ), indicating that the sensible load was fully

20 satisfied and therefore the SATU factors for three cases were zero. The humidity ratio of the

21 supply air was occasionally higher than the desired condition (i.e. $0.0075 \mathrm{~kg} \mathrm{~kg}^{-1}$ dry air), in

22 particular for the regeneration temperature of $60{ }^{\circ} \mathrm{C}$. The SAHRU factors under the 
1 regeneration temperatures of $60{ }^{\circ} \mathrm{C}, 65{ }^{\circ} \mathrm{C}$ and $70{ }^{\circ} \mathrm{C}$ were $24.2 \%, 11.6 \%$ and $6.0 \%$ while the

2 STCs were 100\%, 96.5\%, and 82.6\%, respectively. From Fig. 11, it can also be seen that a

3 lower supply air temperature and a lower humidity ratio than the required conditions were

4 provided during the majority of the test period. This indicated that the use of optimal control

5 by appropriately varying the variables such as the regeneration temperature and supply air

6 flow rate may further increase the STC and reduce the SAHRU factor. The STC could also be

7 increased by increasing the length of the PVT-SAH to increase its outlet air temperature.

8 However, the decision should be made based on the detailed cost-benefit analysis.

PVT-SAH and PCM TES unit to drive the desiccant wheel regeneration is technically feasible

11 under Brisbane weather conditions if the system is appropriately designed and the 12 regeneration temperature is properly selected.

\section{Conclusions}

This paper investigated the feasibility of using the hybrid PVT-SAH and PCM TES unit to drive the regeneration of the rotary desiccant cooling system for residential applications. The feasibility analysis was carried out based on a Solar Decathlon house under Australian Brisbane summer weather conditions in terms of the performance indicators of Solar Thermal Contribution (STC), Supply Air Temperature Unsatisfied (SATU) factor and Supply Air Humidity Ratio Unsatisfied (SAHRU) factor.

The results showed that the sensible cooling load can be satisfied under all three scenarios with the regeneration temperatures of $60{ }^{\circ} \mathrm{C}, 65{ }^{\circ} \mathrm{C}$ and $70{ }^{\circ} \mathrm{C}$ and the SAHRU factor was decreased from $24.2 \%$ to $6.0 \%$ when the regeneration temperature increased from 
$160{ }^{\circ} \mathrm{C}$ to $70{ }^{\circ} \mathrm{C}$. The near-optimal values of the key parameters considered for the hybrid

2 PVT-SAH and PCM TES unit were identified using the response surface method (RSM) and

3 it was found that the STCs of using the hybrid PVT-SAH and PCM TES unit to drive the

4 regeneration of the rotary desiccant cooling system were $100 \%, 96.5 \%$ and $82.6 \%$ under

5 different regeneration temperatures of $60{ }^{\circ} \mathrm{C}, 65{ }^{\circ} \mathrm{C}$ and $70{ }^{\circ} \mathrm{C}$, respectively. The results from

6 this study demonstrated the technical feasibility of using the hybrid PVT-SAH and PCM TES

7 unit to drive the desiccant wheel regeneration under Australian Brisbane weather conditions if

8 the system is well designed. The performance could be further improved through the use of

9 optimal control strategies.

\section{References}

Ali, M., Vukovic, V., Sahir, M. H., \& Basciotti, D. (2013). Development and validation of a desiccant wheel model calibrated under transient operating conditions. Applied Thermal Engineering, 61(2), 469-480.

Angrisani, G., Minichiello, F., Roselli, C., \& Sasso, M. (2012). Experimental analysis on the dehumidification and thermal performance of a desiccant wheel. Applied Energy, 92, 563-572.

Baniyounes, A. M., Liu, G., Rasul, M. G., \& Khan, M. M. K. (2013). Comparison study of solar cooling technologies for an institutional building in subtropical Queensland, Australia.

20 Renewable and Sustainable Energy Reviews, 23, 421-430.

21 Baniyounes, A. M., Rasul, M. G., \& Khan, M. M. K. (2013). Experimental assessment of a 22 solar desiccant cooling system for an institutional building in subtropical Queensland, 
1 Australia. Energy and Buildings, 62, 78-86.

2 Beccali, M., Finocchiaro, P., \& Nocke, B. (2009). Energy and economic assessment of

3 desiccant cooling systems coupled with single glazed air and hybrid PV/thermal solar

4 collectors for applications in hot and humid climate. Solar Energy, 83(10), 1828-1846.

5 Bergman, T. L., Incropera, F. P., DeWitt, D. P., \& Lavine, A. S. (2011). Fundamentals of heat 6 and mass transfer. John Wiley \& Sons.

7 Charvát, P., Klimeš, L., \& Ostrý, M. (2014). Numerical and experimental investigation of a

8 PCM-based thermal storage unit for solar air systems. Energy and Buildings, 68, 488-497.

9 DesignBuilder Software, V 5.0.3.007. DesignBuilder Software Ltd

10 (www.designbuilder.co.uk), Gloucestershire (UK) 2017.

11 De Antonellis, S., Intini, M., \& Joppolo, C. M. (2015). Desiccant wheels effectiveness

12 parameters: correlations based on experimental data. Energy and Buildings, 103, 296-306.

13 De Antonellis, S., Intini, M., Joppolo, C. M., Molinaroli, L., \& Romano, F. (2015). Desiccant

14 wheels for air humidification: an experimental and numerical analysis. Energy Conversion 15 and Management, 106, 355-364.

16 Design Expert Software, V 8.0.5. Stat-Ease Inc., Minneapolis (USA), 2010.

17 Dolado, P., Lazaro, A., Marin, J. M., \& Zalba, B. (2011). Characterization of melting and 18 solidification in a real scale PCM-air heat exchanger: Numerical model and experimental 19 validation. Energy Conversion and Management, 52(4), 1890-1907.

20 Duffie, J. A., \& Beckman, W. A. (2013). Solar engineering of thermal processes. John Wiley 21 \& Sons.

22 Eicker, U., Schürger, U., Köhler, M., Ge, T., Dai, Y., Li, H., \& Wang, R. (2012). Experimental 
1 investigations on desiccant wheels. Applied Thermal Engineering, 42, 71-80.

2 Enteria, N., Yoshino, H., Satake, A., Mochida, A., Takaki, R., Yoshie, R., \& Baba, S. (2010).

3 Development and construction of the novel solar thermal desiccant cooling system

4 incorporating hot water production. Applied Energy, 87(2), 478-486.

5 Enteria, N., Yoshino, H., Satake, A., Mochida, A., Takaki, R., Yonekura, H., Yoshie R., \&

6 Baba, S. (2011). Initial operation and performance evaluation of the developed solar thermal

7 and electric desiccant cooling system. Experimental Heat Transfer, 24(1), 59-87.

8 Fan, W., Kokogiannakis, G., Ma, Z., \& Cooper, P. (2017). Development of a dynamic model

9 for a hybrid photovoltaic thermal collector-Solar air heater with fins. Renewable Energy, 101,

$10 \quad 816-834$.

11 Fiorentini, M. (2016). Hybrid model predictive control of residential heating, ventilation and

12 air conditioning systems with on-site energy generation and storage, $\mathrm{PhD}$ thesis, University of

13 Wollongong.

14 Fiorentini, M., Wall, J., Ma, Z., Braslavski, J., \& Cooper, P. (2017). Hybrid model predictive

15 control of a residential HVAC system with on-site thermal energy generation and storage.

16 Applied Energy, 187, 465-479.

17 Ge, T. S., Li, Y., Wang, R. Z., \& Dai, Y. J. (2009). Experimental study on a two-stage rotary

18 desiccant cooling system. International Journal of Refrigeration, 32(3), 498-508.

19 Ge, T. S., Ziegler, F., \& Wang, R. Z. (2010). A mathematical model for predicting the

20 performance of a compound desiccant wheel (A model of compound desiccant wheel).

21 Applied Thermal Engineering, 30(8), 1005-1015.

22 Gnielinski, V. (1976). New equations for heat and mass transfer in turbulent pipe and channel 
1 flow. International Journal of Chemical Engineering, 16, 359-368.

2 Jani, D. B., Mishra, M., \& Sahoo, P. K. (2015). Performance studies of hybrid solid

3 desiccant-vapor compression air-conditioning system for hot and humid climates. Energy and

4 Buildings, 102, 284-292.

5 Jani, D. B., Mishra, M., \& Sahoo, P. K. (2016a). Solid desiccant air conditioning-A state of

6 the art review. Renewable and Sustainable Energy Reviews, 60, 1451-1469.

7 Jani, D. B., Mishra, M., \& Sahoo, P. K. (2016b). Performance analysis of hybrid solid 8 desiccant-vapor compression air conditioning system in hot and humid weather of India.

$9 \quad$ Building Services Engineering Research and Technology, 37(5), 523-538.

10 Jani, D. B., Mishra, M., \& Sahoo, P. K. (2016c). Experimental investigation on solid 11 desiccant-vapor compression hybrid air-conditioning system in hot and humid weather. 12 Applied Thermal Engineering, 104, 556-564.

13 Jia, C. X., Dai, Y. J., Wu, J. Y., \& Wang, R. Z. (2006). Experimental comparison of two 14 honeycombed desiccant wheels fabricated with silica gel and composite desiccant material. 15 Energy Conversion and Management, 47(15), 2523-2534.

Khalid, A., Mahmood, M., Asif, M., \& Muneer, T. (2009). Solar assisted, pre-cooled hybrid desiccant cooling system for Pakistan. Renewable Energy, 34(1), 151-157.

18 Klein, S. A. (2010). TRNSYS 17: A transient system simulation program. Madison, USA: Solar Energy Laboratory, University of Wisconsin.

20 La, D., Dai, Y. J., Li, Y., Wang, R. Z., \& Ge, T. S. (2010). Technical development of rotary 21 desiccant dehumidification and air conditioning: a review. Renewable and Sustainable Energy 22 Reviews, 14(1), 130-147. 
1 Lin, W., Ma, Z., Sohel, M. I., \& Cooper, P. (2014). Development and evaluation of a ceiling

2 ventilation system enhanced by solar photovoltaic thermal collectors and phase change

3 materials. Energy Conversion and Management, 88, 218-230.

4 Lopez, J. P. A., Kuznik, F., Baillis, D., \& Virgone, J. (2013). Numerical modeling and

5 experimental validation of a PCM to air heat exchanger. Energy and Buildings, 64, 415-422.

6 Ma, Z., Lin, W., \& Sohel, M. I. (2016). Nano-enhanced phase change materials for improved

7 building performance. Renewable and Sustainable Energy Reviews, 58, 1256-1268.

8 Mei, L., Infield, D., Eicker, U., Loveday, D., \& Fux, V. (2006). Cooling potential of ventilated

9 PV façade and solar air heaters combined with a desiccant cooling machine. Renewable energy, 31(8), 1265-1278.

Montgomery, D. C. (2008). Design and analysis of experiments. John Wiley \& Sons.

Pesaran, A. A., \& Mills, A. F. (1987). Moisture transport in silica gel packed beds—I.

13 Theoretical study. International Journal of Heat and Mass Transfer, 30(6), 1037-1049.

14 Rubitherm GmbH. (2016). Available at: www.rubitherm.com [Accessed 01.Jun.2016].

15 Sheng, Y., Zhang, Y., Sun, Y., Fang, L., Nie, J., \& Ma, L. (2014). Experimental analysis and regression prediction of desiccant wheel behavior in high temperature heat pump and desiccant wheel air-conditioning system. Energy and Buildings, 80, 358-365.

Subasi, A., Sahin, B., \& Kaymaz, I. (2016). Multi-objective optimization of a honeycomb heat sink using Response Surface Method. International Journal of Heat and Mass Transfer, 101, 295-302.

Wang, J. M., Lan, S., \& Li, W. K. (2014). Numerical simulation and process optimization of an aluminum holding furnace based on response surface methodology and uniform design. 
1 Energy, 72, 521-535.

2 White, S. D., Kohlenbach, P., \& Bongs, C. (2009). Indoor temperature variations resulting

3 from solar desiccant cooling in a building without thermal backup. International Journal of

4 Refrigeration, 32(4), 695-704.

5 Zeng, D. Q., Li, H., Dai, Y. J., \& Xie, A. X. (2014). Numerical analysis and optimization of a

6 solar hybrid one-rotor two-stage desiccant cooling and heating system. Applied Thermal

7 Engineering, 73(1), 474-483. 
Table 1 Summary of the desiccant wheel parameters, operating conditions and regeneration temperatures reported in previous studies

\begin{tabular}{|c|c|c|c|c|c|c|c|c|c|c|c|c|c|c|}
\hline \multirow[b]{2}{*}{ Reference } & \multicolumn{5}{|c|}{ Desiccant wheel parameters } & \multicolumn{5}{|c|}{ Operating Parameters } & \multirow[b]{2}{*}{$\begin{array}{c}\text { Regeneration } \\
\text { temperature } \\
\left({ }^{\circ} \mathrm{C}\right)\end{array}$} & \multicolumn{3}{|c|}{ Performance indicators } \\
\hline & $\begin{array}{c}\text { Diameter } \\
\text { (m) }\end{array}$ & $\begin{array}{c}\text { Thickness } \\
\text { (m) }\end{array}$ & $\begin{array}{l}\text { Area } \\
\text { ratio }^{1}\end{array}$ & $\begin{array}{c}\text { Desiccant } \\
\text { material }^{2}\end{array}$ & Stage & $\begin{array}{c}T_{p r o, a, i n} \\
\left({ }^{\circ} \mathrm{C}\right)\end{array}$ & $\begin{array}{c}Y_{\text {pro,a,in }} \\
\left(\mathrm{kg} \mathrm{kg}^{-1}\right)\end{array}$ & $\begin{array}{c}\text { Rotation } \\
\text { speed } \\
\left(\mathrm{r} \mathrm{h}^{-1}\right)\end{array}$ & $\begin{array}{l}\text { Flow } \\
\text { ratio }^{3}\end{array}$ & $\begin{array}{l}\dot{m}_{\text {pro,a }} \\
\left(\mathrm{kg} \mathrm{h}^{-1}\right)\end{array}$ & & $\begin{array}{c}\text { MRC (kg } \\
\left.\mathrm{h}^{-1}\right)\end{array}$ & DCOP & $\eta$ \\
\hline Jia, Dai, Wu, \& Wang & 0.40 & 0.20 & $1: 3$ & SG & 1 & 30.0 & 0.0160 & - & $1: 3$ & 900 & $60.0-120.0$ & 0.90-8.55 & - & 0.06-0.59 \\
\hline \multirow[t]{2}{*}{ (2016) } & & & & $\mathrm{CD}$ & & 30.0 & 0.0160 & - & $1: 3$ & 900 & $60.0-120.0$ & 1.98-10.6 & - & $0.14-0.74$ \\
\hline & & & & & & & & & & & & 2 & & \\
\hline Ge, Li, Wang, \& Dai & 0.26 & 0.10 & $1: 3$ & $\mathrm{CD}$ & 2 & 35.0 & 0.0014 & 8 & $1: 2.4$ & 432 & $50.0-90.0$ & 1.38-3.63 & - & $0.23-0.60$ \\
\hline \multirow[t]{2}{*}{ (2009) } & & & & & & 30.0 & 0.0016 & & & & & $1.74-3.91$ & - & $0.25-0.56$ \\
\hline & & & & & & 35.0 & 0.0023 & & & & & 1.99-6.48 & - & $0.20-0.65$ \\
\hline Angrisani et al. & 0.70 & 0.20 & $2: 3$ & SG & 1 & 31.6 & 0.0013 & 12 & $1: 1$ & 960 & $37.0-72.0$ & $1.7-5.1$ & $0.25-0$ & $0.15-0.46$ \\
\hline (2012) & & & & & & & & & & & & & .95 & \\
\hline \multirow[t]{3}{*}{ Eicker et al. (2012) } & 0.87 & 0.14 & $1: 1$ & SG & 1 & 32.0 & 0.0120 & 85 & $1: 0.75$ & 2400 & $60.0-90.0$ & $9.60-13.6$ & - & $0.54-0.58$ \\
\hline & 0.895 & 0.25 & $1: 1$ & LC & 1 & 32.0 & 0.0120 & 24 & 1:0.75 & 2400 & $45.0-70.0$ & 8 & - & $0.17-0.23$ \\
\hline & & & & & & & & & & & & $4.80-6.48$ & & \\
\hline Ali et al. (2013) & 0.32 & 0.20 & $1: 1$ & SG & 1 & 31.0 & 0.0100 & 36 & $1: 1$ & 346 & $45-120$ & $0.49-2.02$ & - & 0.15-0.62 \\
\hline \multirow[t]{2}{*}{ Sheng et al. (2014) } & 0.45 & 0.20 & $1: 3$ & SG & 1 & $28.2-4$ & 0.0140 & 15 & $1.2: 1$ & 325 & $58.1-64.8$ & 0.98-1.34 & $0.21-0$ & $0.262-0.35$ \\
\hline & & & & & & 0.2 & & & $-1: 1$ & & & & .27 & 9 \\
\hline De Antonellis, Intini, & 0.60 & 0.20 & $1: 1$ & SMS & 1 & $11.9-1$ & $0.0045-$ & 15.5 & $1: 1$ & $1078-10$ & $35.1-66.0$ & 2.59-4.24 & - & $0.52-0.85$ \\
\hline Joppolo, Molinaroli, & & & & & & 2.9 & 0.0046 & & & 83 & & & & \\
\hline \& Romano (2015) & & & & & & & & & & & & & & \\
\hline $\begin{array}{l}\text { De Antonellis, Intini, } \\
\text { \& Joppolo (2015) }\end{array}$ & 0.60 & 0.20 & $1: 1$ & SMS & 1 & 25.0 & 0.0120 & 15 & $1: 1$ & 1100 & 44.4-78.6 & $2.48-6.00$ & - & $0.20-0.49$ \\
\hline
\end{tabular}

${ }^{1}$ Area ratio - ratio of the area of the regeneration side to that of the process side of a desiccant wheel.

${ }^{2}$ CD - composite desiccant; LC - lithium chloride; SG - silica gel; SMS - synthesized metal silicate.

${ }^{3}$ Flow ratio - ratio of the flow rate of the regeneration air to that of the process air. 
Table 2 Operation modes of the integrated desiccant cooling system

\begin{tabular}{|c|c|c|}
\hline Mode & Description & Working principle \\
\hline Mode I & $\begin{array}{l}\text { Regeneration } \\
\text { with PVT-SAH } \\
\text { direct supply }\end{array}$ & $\begin{array}{l}\text { The heated air from the PVT-SAH is directly used for } \\
\text { desiccant wheel regeneration. The electric heater is used if } \\
\text { the air temperature cannot reach the required setting. }\end{array}$ \\
\hline Mode II & $\begin{array}{l}\text { Regeneration } \\
\text { with PVT-SAH } \\
\text { direct supply \& } \\
\text { TES charging }\end{array}$ & $\begin{array}{l}\text { A fraction of the heated air from the PVT-SAH is used for } \\
\text { the desiccant wheel regeneration and the rest is used for the } \\
\text { TES charging. }\end{array}$ \\
\hline Mode III & TES charging & $\begin{array}{l}\text { The heated air from the PVT-SAH is used to charge the PCM } \\
\text { TES unit if there is no demand during the daytime. }\end{array}$ \\
\hline Mode IV & $\begin{array}{l}\text { Regeneration } \\
\text { with the TES } \\
\text { discharging }\end{array}$ & $\begin{array}{l}\text { The PCM TES unit is discharged for desiccant wheel } \\
\text { regeneration if there is a cooling demand during nighttime. }\end{array}$ \\
\hline Mode V & Space heating & $\begin{array}{l}\text { The heated air from the PVT-SAH is directly used for space } \\
\text { heating or is directed into the TES unit (Note: may need to } \\
\text { use another PCM with different melting temperature) and } \\
\text { then used later for space heating. }\end{array}$ \\
\hline
\end{tabular}

Table 3 Occupants schedules used in the simulation

\begin{tabular}{cccccc}
\hline \multirow{2}{*}{ Time } & \multicolumn{2}{c}{ Living space } & \multicolumn{2}{c}{ Sleeping space } & \multirow{2}{*}{ Status of PCM TES unit } \\
\cline { 2 - 5 } & Occupant & Air-conditioned & Occupant & Air-conditioned & \\
\hline 8:00- 17:00 & 0 & No & 0 & No & Charging \\
17:00 - 23:00 & 2 & Yes if needed & 0 & No & Discharging if needed \\
23:00-8:00 & 0 & No & 2 & Yes if needed & Discharging if needed \\
\hline
\end{tabular}

Table 4 Levels of the main parameters considered in the RSM design

\begin{tabular}{lllll}
\hline \multirow{2}{*}{ Variables } & \multicolumn{3}{c}{ Levels } \\
\cline { 3 - 5 } & & -1 & 0 & +1 \\
\hline \multirow{2}{*}{ PCM type } & Scenario A $\left(\mathrm{T}_{\text {reg }}=65{ }^{\circ} \mathrm{C}\right)$ & RT60 & RT65 & RT70HC \\
\cline { 2 - 5 } & Scenario B $\left(\mathrm{T}_{\text {reg }}=60{ }^{\circ} \mathrm{C}\right)$ & RT55 & RT60 & RT65 \\
\cline { 2 - 5 } & Scenario C $\left(\mathrm{T}_{\text {reg }}=70{ }^{\circ} \mathrm{C}\right)$ & RT60 & RT65 & RT70HC \\
\hline Length of the PCM TES unit $(\mathrm{m})$ & 3.0 & 5.0 & 7.0 \\
\hline Size of the air gap ${ }^{1}(\mathrm{~mm})$ & 5.0 & 12.5 & 20.0 \\
\hline Air flow rate $\left(\mathrm{kg} \mathrm{h}^{-1}\right)$ & 500 & 750 & 1000 \\
\hline${ }^{1}$ The size of the air gap between the glass cover and the PV plate/absorber plate of the PVT-SAH.
\end{tabular}


Table 5 Thermophysical properties of the PCMs considered (Rubitherm GmbH, 2016)

\begin{tabular}{lllll}
\hline Parameter & RT55 & RT60 & RT65 & RT70HC \\
\hline Melting range $\left({ }^{\circ} \mathrm{C}\right)$ & $51-57$ & $55-61$ & $57-68$ & $69-71$ \\
Congealing range $\left({ }^{\circ} \mathrm{C}\right)$ & $56-57$ & $61-55$ & $67-58$ & $71-69$ \\
Specific heat $\left(\mathrm{kJ} \mathrm{kg}^{-1} \mathrm{~K}^{-1}\right)$ & 2.0 & 2.0 & 2.0 & 2.0 \\
Thermal conductivity $\left(\mathrm{W} \mathrm{m}^{-1} \mathrm{~K}^{-1}\right)$ & 0.2 & 0.2 & 0.2 & 0.2 \\
Heat storage capacity $\left(\mathrm{kJ} \mathrm{kg}^{-1}\right)$ & 170 & 160 & 150 & 260 \\
Density solid/liquid $\left(\mathrm{kg} \mathrm{m}^{-3}\right)$ & $880 / 770$ & $880 / 770$ & $880 / 780$ & $880 / 770$ \\
\hline
\end{tabular}

Table 6 Specifications of the rotary desiccant cooling system, hybrid PVT-SAH and PCM TES unit

\begin{tabular}{|c|c|c|c|}
\hline Component & Parameter & Value & Source \\
\hline \multirow{4}{*}{ PVT-SAH } & Length (m) & 6.0 & - \\
\hline & Width (m) & 4.0 & Roof width \\
\hline & Slope (degree) & 18.4 & Roof slope \\
\hline & Ratio of PVT to SAH & $6: 4$ & - \\
\hline \multirow{6}{*}{$\begin{array}{l}\text { Desiccant } \\
\text { wheel }\end{array}$} & Diameter (m) & 0.4 & - \\
\hline & Thickness (m) & 0.2 & - \\
\hline & Rotation speed $\left(\mathrm{r} \mathrm{h}^{-1}\right)$ & 12 & - \\
\hline & Desiccant & $\begin{array}{l}\text { Silica gel } \\
\text { (RD) }\end{array}$ & - \\
\hline & Area ratio of regeneration side to process side & $1: 1$ & - \\
\hline & Flow rate ratio of regeneration air to process air & $1: 1$ & - \\
\hline \multirow{5}{*}{$\begin{array}{l}\text { PCM TES } \\
\text { unit }\end{array}$} & Width (m) & 0.44 & Charvát, et al. (2014) \\
\hline & Thickness of the PCM panel (mm) & 20 & Charvát, et al. (2014) \\
\hline & Air channel (mm) & 10 & Dolado et al. (2010) \\
\hline & Number of PCM layers & 20 & $\begin{array}{l}\text { Based on the height of } \\
0.6 \mathrm{~m}\end{array}$ \\
\hline & Rugosity (mm) & 0.25 & Dolado et al. (2010) \\
\hline \multirow{2}{*}{$\begin{array}{l}\text { Indirect } \\
\text { evaporative } \\
\text { cooler }\end{array}$} & Wet-bulb temperature effectiveness & 0.7 & White et al. (2009) \\
\hline & Flow ratio of secondary air to primary air & 0.375:1.0 & White et al. (2009) \\
\hline $\begin{array}{l}\text { Heat } \\
\text { recovery unit }\end{array}$ & Effectiveness & 0.8 & White et al. (2009) \\
\hline
\end{tabular}


Table 7 Simulation design and simulation results - Scenario A

\begin{tabular}{llllll}
\hline \multirow{2}{*}{ Length (m) } & \multirow{2}{*}{ Air gap $(\mathrm{mm})$} & \multirow{2}{*}{ Flow rate $\left(\mathrm{kg} \mathrm{h}^{-1}\right)$} & \multicolumn{3}{c}{ STC $(\%)$} \\
\cline { 4 - 6 } & & & RT60 & RT65 & RT70HC \\
\hline 3 & 5.0 & 500 & 71.5 & 69.3 & 61.7 \\
7 & 5.0 & 500 & 91.0 & 92.1 & 86.4 \\
3 & 20.0 & 500 & 75.3 & 73.3 & 67.6 \\
7 & 20.0 & 500 & 93.0 & 95.7 & 91.4 \\
3 & 5.0 & 1000 & 57.9 & 52.2 & 33.3 \\
7 & 5.0 & 1000 & 78.2 & 72.9 & 64.4 \\
3 & 20.0 & 1000 & 61.0 & 56.7 & 36.9 \\
7 & 20.0 & 1000 & 82.8 & 78.1 & 68.9 \\
3 & 12.5 & 750 & 66.5 & 64.4 & 51.2 \\
7 & 12.5 & 750 & 88.3 & 87.3 & 77.8 \\
5 & 5.0 & 750 & 76.9 & 73.8 & 63.8 \\
5 & 20.0 & 750 & 81.0 & 78.2 & 69.3 \\
5 & 12.5 & 500 & 90.2 & 87.3 & 80.0 \\
5 & 12.5 & 1000 & 73.6 & 69.8 & 55.0 \\
5 & 12.5 & 750 & 80.9 & 78.0 & 69.0 \\
\hline
\end{tabular}

Table 8 Coefficients of the response surface models - Scenario A

\begin{tabular}{ccccccccc}
\hline & $b_{0}$ & $b_{1}$ & $b_{2}$ & $b_{3}$ & $b_{11}$ & $b_{22}$ & $b_{12}$ & $R^{2}$ \\
\hline RT60 & 54.7946 & 11.2848 & 1.0088 & -0.0338 & -0.7253 & -0.0290 & $1.36 \mathrm{E}-3$ & 0.9912 \\
RT65 & 55.9970 & 11.7443 & 1.0088 & -0.0420 & -0.7253 & -0.0290 & $1.36 \mathrm{E}-3$ & 0.9943 \\
RT70HC & 51.0256 & 13.1424 & 1.0088 & -0.0582 & -0.7253 & -0.0290 & $1.36 \mathrm{E}-3$ & 0.9954 \\
\hline
\end{tabular}

Table 9 Optimal designs identified for Scenarios A, B and C

\begin{tabular}{cccc}
\hline & Scenario A & Scenario B & Scenario C \\
\hline Length $(\mathrm{m})$ & 7.0 & 7.0 & 7.0 \\
Air flow rate $\left(\mathrm{kg} \mathrm{h}^{-1}\right)$ & 500 & 500 & 500 \\
Air gap (mm) & 17.4 & 16.9 & 16.4 \\
PCM type & RT65 & RT65 & RT65 \\
STC (RSM model) & $95.2 \%$ & $100.5 \%$ & $85.6 \%$ \\
STC (confirmation test) & $96.5 \%$ & $100.0 \%$ & $82.6 \%$ \\
\hline
\end{tabular}




\section{Figure captions}

Fig. 1 Schematic of a desiccant cooling system with integrated hybrid PVT-SAH and PCM TES unit.

Fig. 2 Scheme of the air-based PCM TES unit.

Fig. 3 Outline of the research method employed in this study.

Fig. 4 The configuration of the hybrid PVT-SAH.

Fig. 5 Schematic of the nodes in the modelling of the PCM TES unit.

Fig. 6 Comparison between simulation results and experimental data under the air flow rate of $240 \mathrm{~m}^{3} \mathrm{~h}^{-1}$.

Fig. 7 Weather conditions of the selected consecutive five summer days in Brisbane.

Fig. 8 Enthalpy-temperature relationship of the PCM RT70HC (Rubitherm GmbH, 2016).

Fig. 9 Variation in STC with the changes of the key parameters under the regeneration temperature of $65^{\circ} \mathrm{C}$.

Fig. 10 Results of the confirmation test using the optimal values identified - Scenario A.

Fig. 11 Supply air conditions under different regeneration temperatures. 


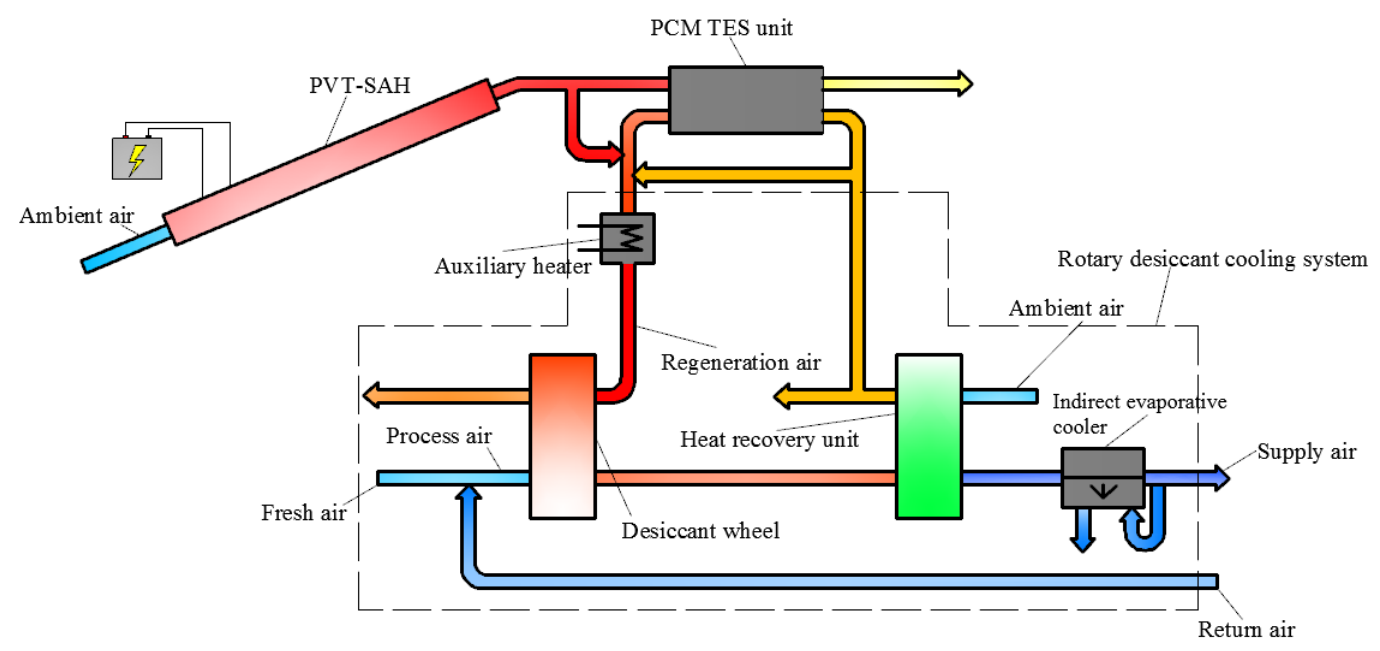

Fig. 1 Schematic of a desiccant cooling system with integrated hybrid PVT-SAH and PCM TES unit.

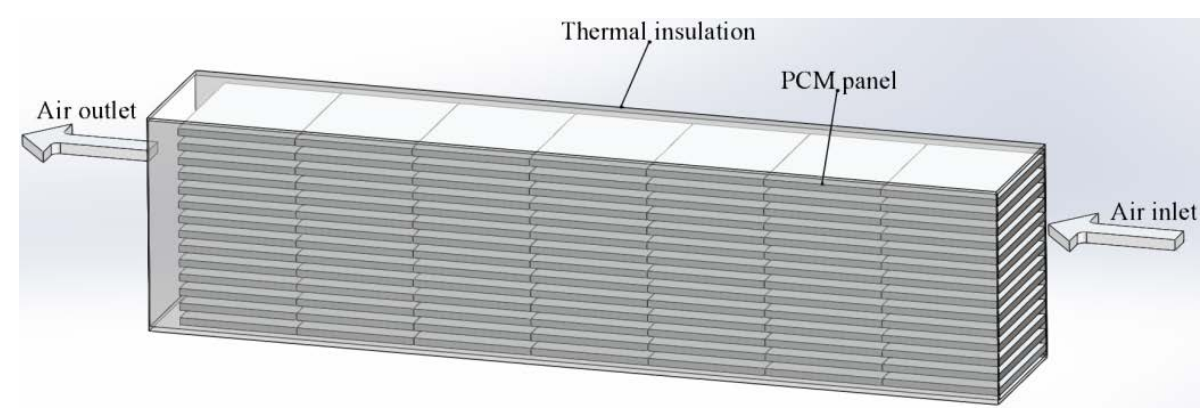

Fig. 2 Scheme of the air-based PCM TES unit. 


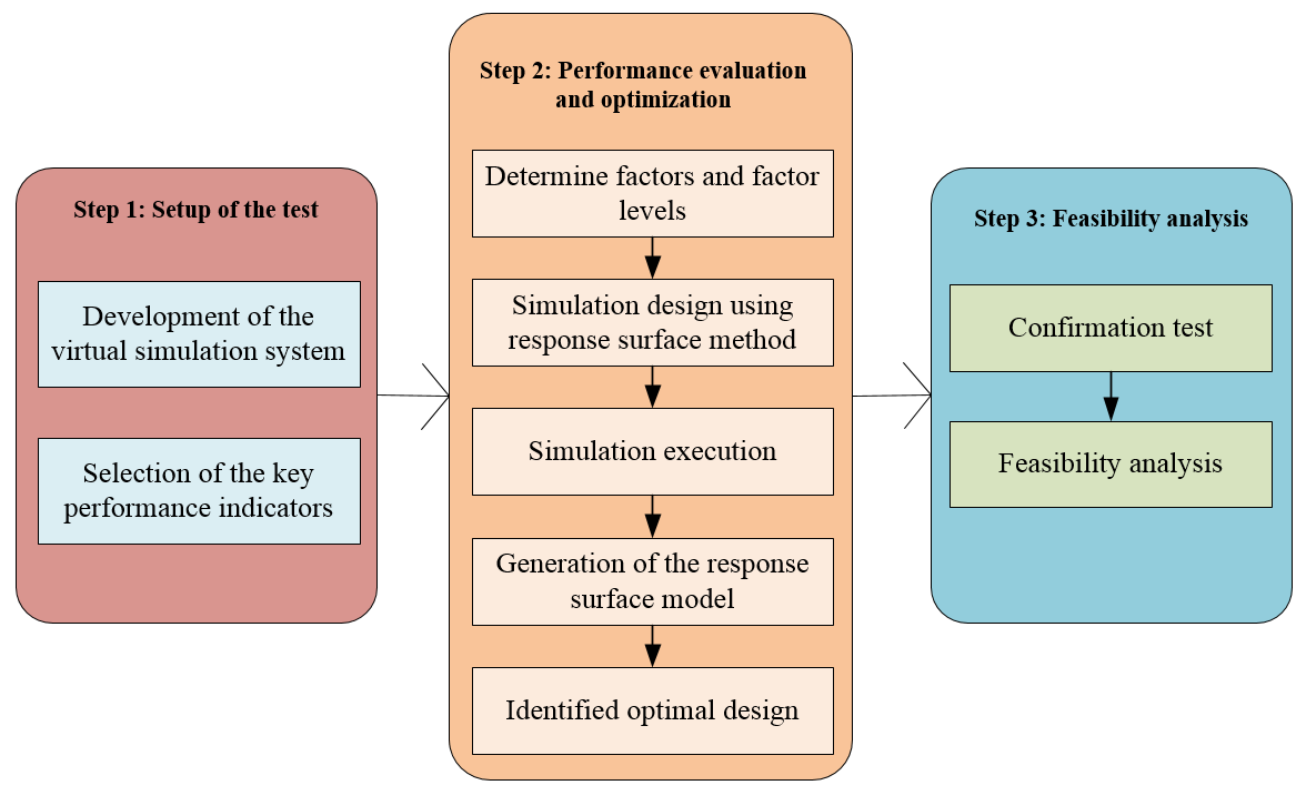

Fig. 3 Outline of the research method employed in this study.

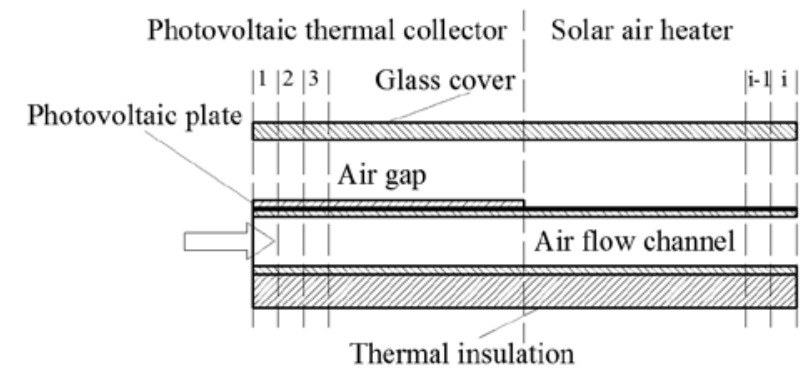

(a) Front view

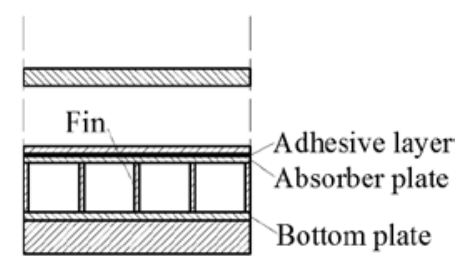

(b) Side view

Fig. 4 The configuration of the hybrid PVT-SAH.

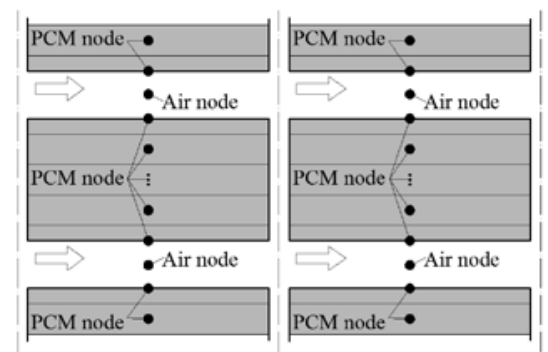

Fig. 5 Schematic of the nodes in the modelling of the PCM TES unit. 


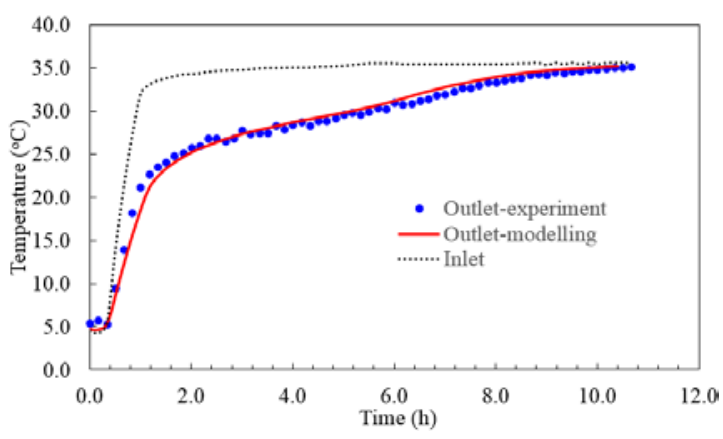

a) Charge process

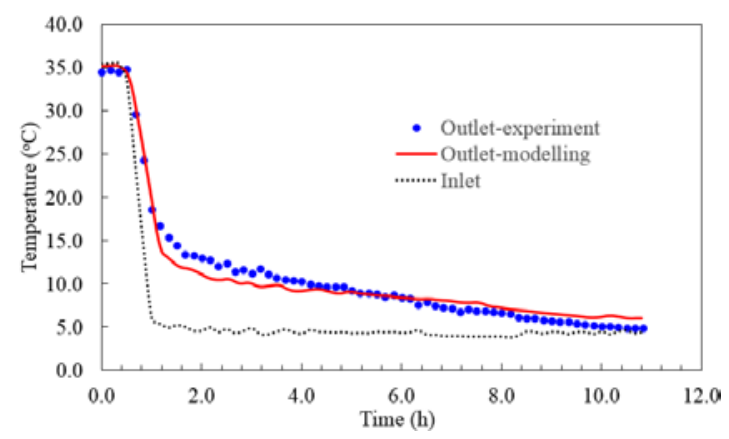

b) Discharge process

Fig. 6 Comparison between simulation results and experimental data under the air flow rate of $240 \mathrm{~m}^{3} \mathrm{~h}^{-1}$.

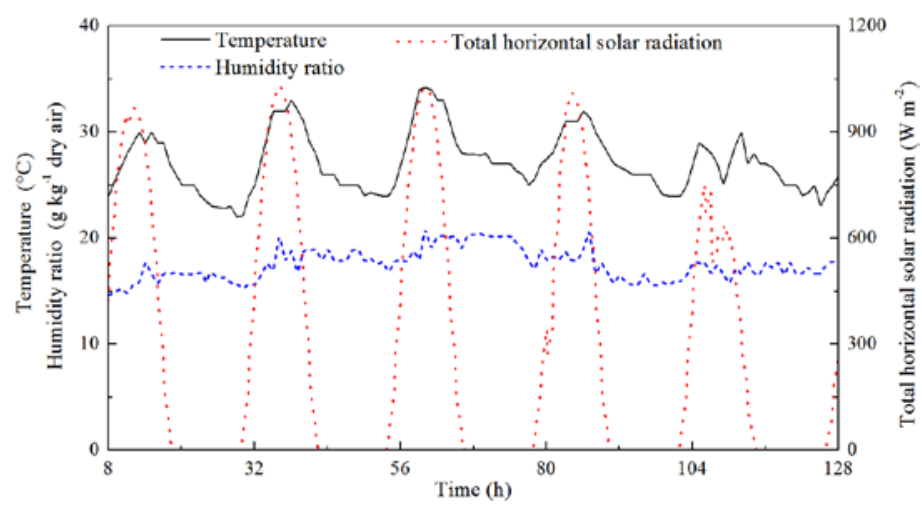

Fig. 7 Weather conditions of the selected consecutive five summer days in Brisbane.

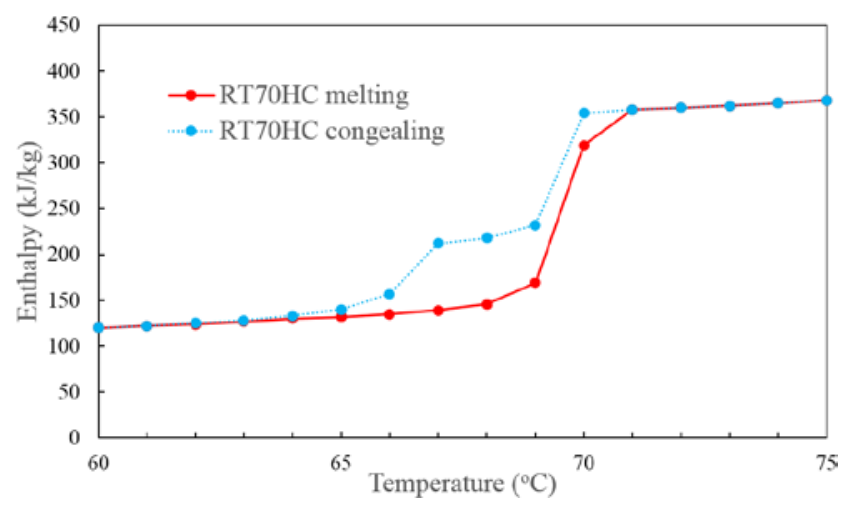

Fig. 8 Enthalpy-temperature relationship of the PCM RT70HC (Rubitherm GmbH, 2016). 


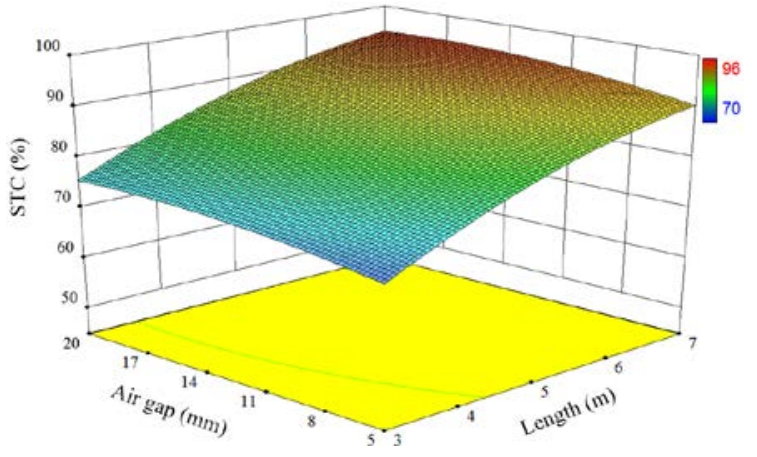

a) RT60 and flow rate of 500 $\mathrm{kg} \mathrm{h}^{-1}$

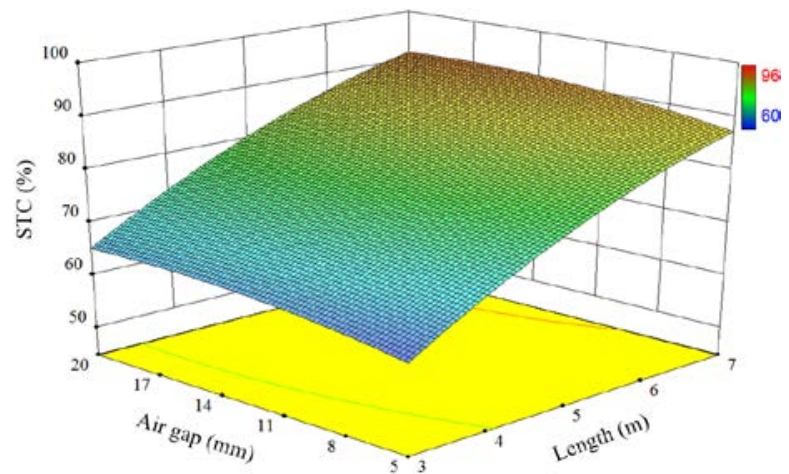

c) RT70HC and flow rate of $500 \mathrm{~kg} \mathrm{~h}^{-1}$

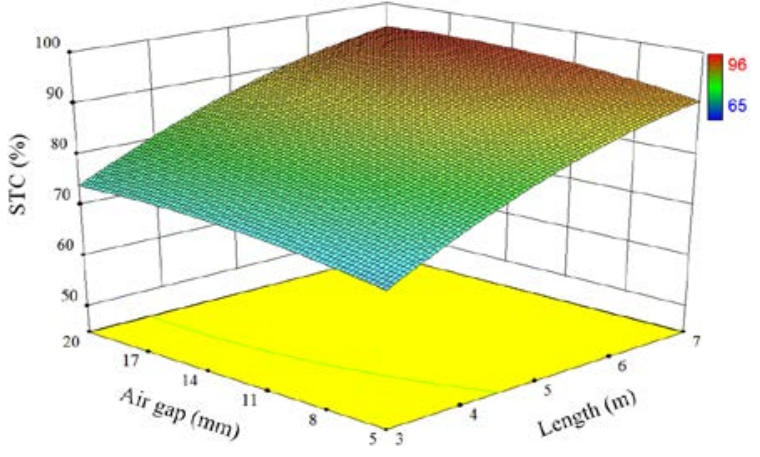

b) RT65 and flow rate of $500 \mathrm{~kg} \mathrm{~h}^{-1}$

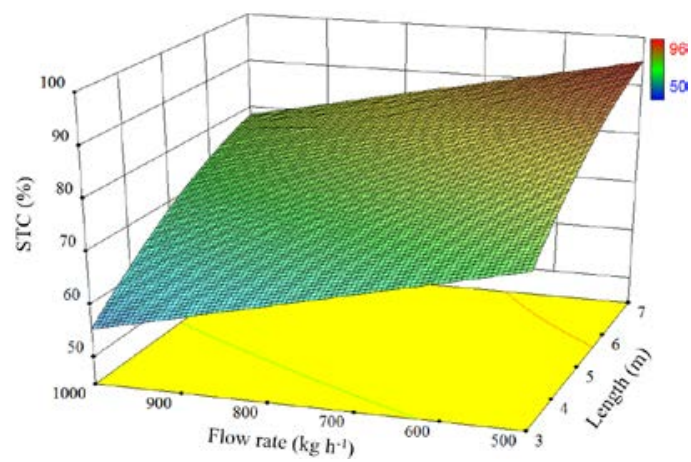

d) RT65 and air gap of $16.0 \mathrm{~mm}$

Fig. 9 Variation in STC with the changes of the key parameters under the regeneration temperature of $65{ }^{\circ} \mathrm{C}$.

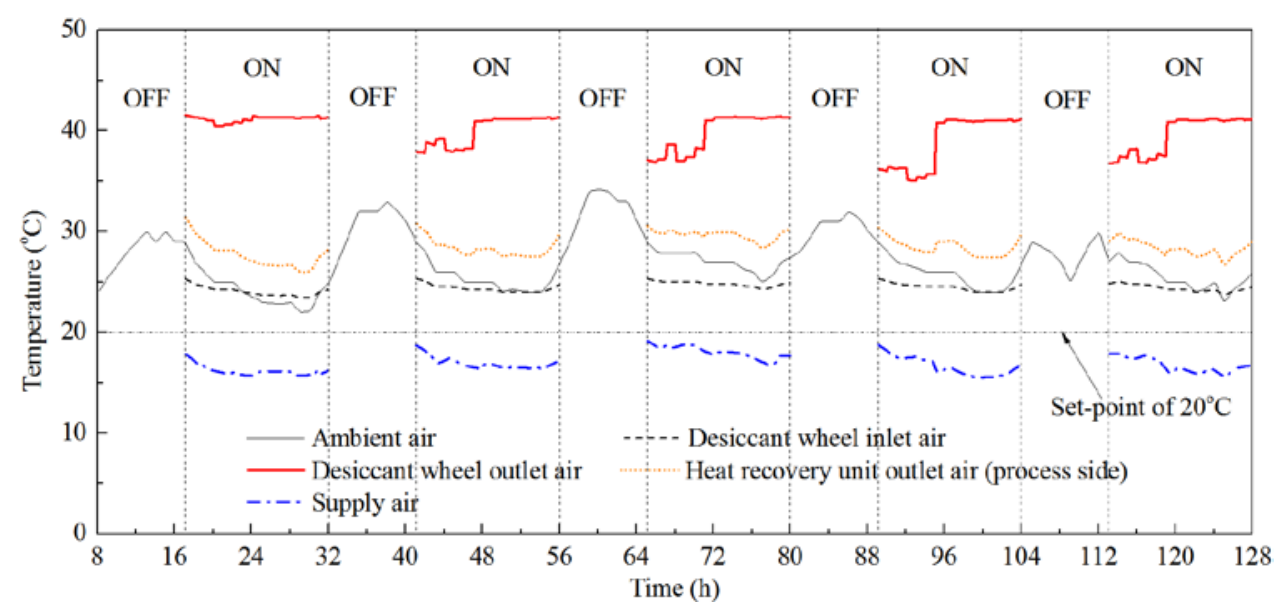

a) Air temperature 


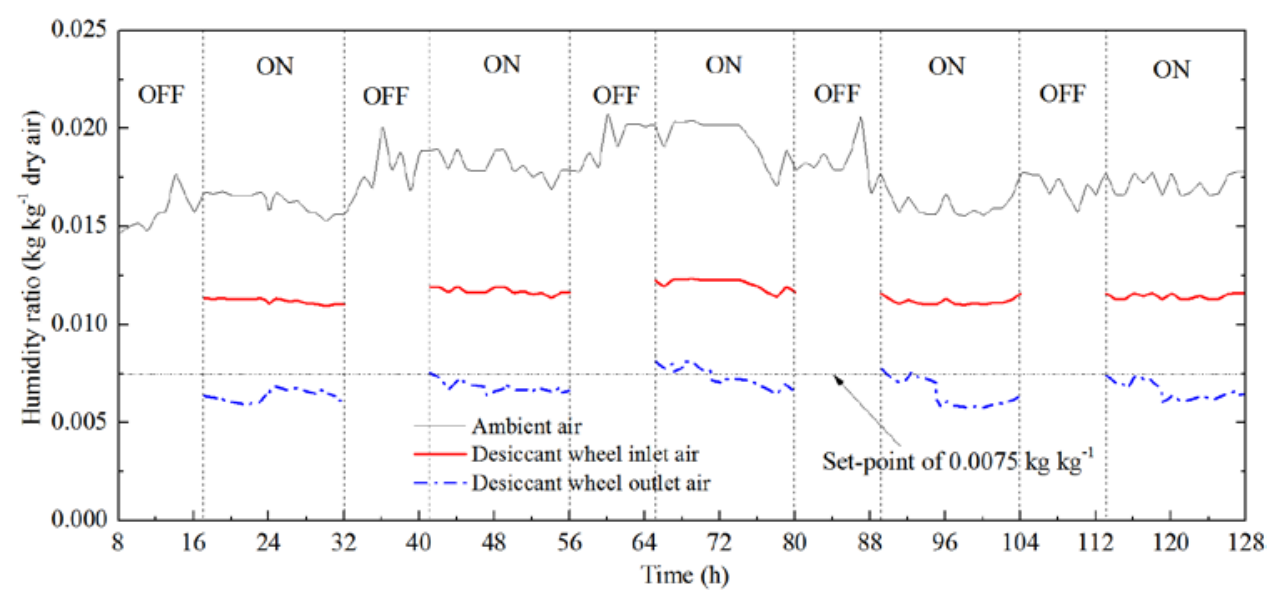

b) Air humidity ratio

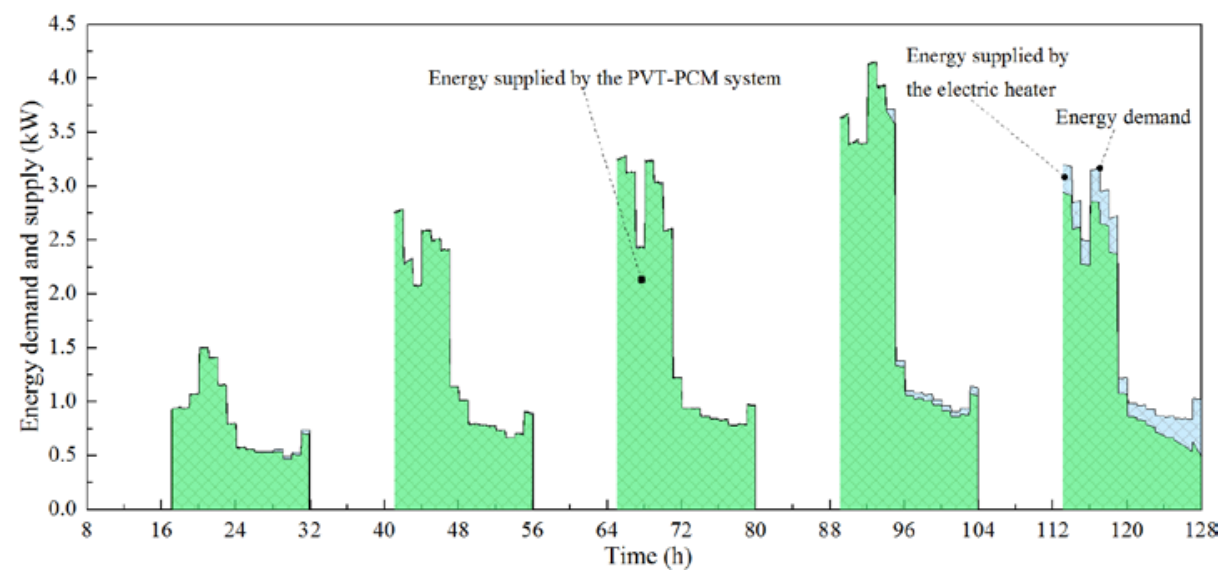

c) Thermal energy demand and supply

Fig. 10 Results of the confirmation test using the optimal values identified - Scenario A.

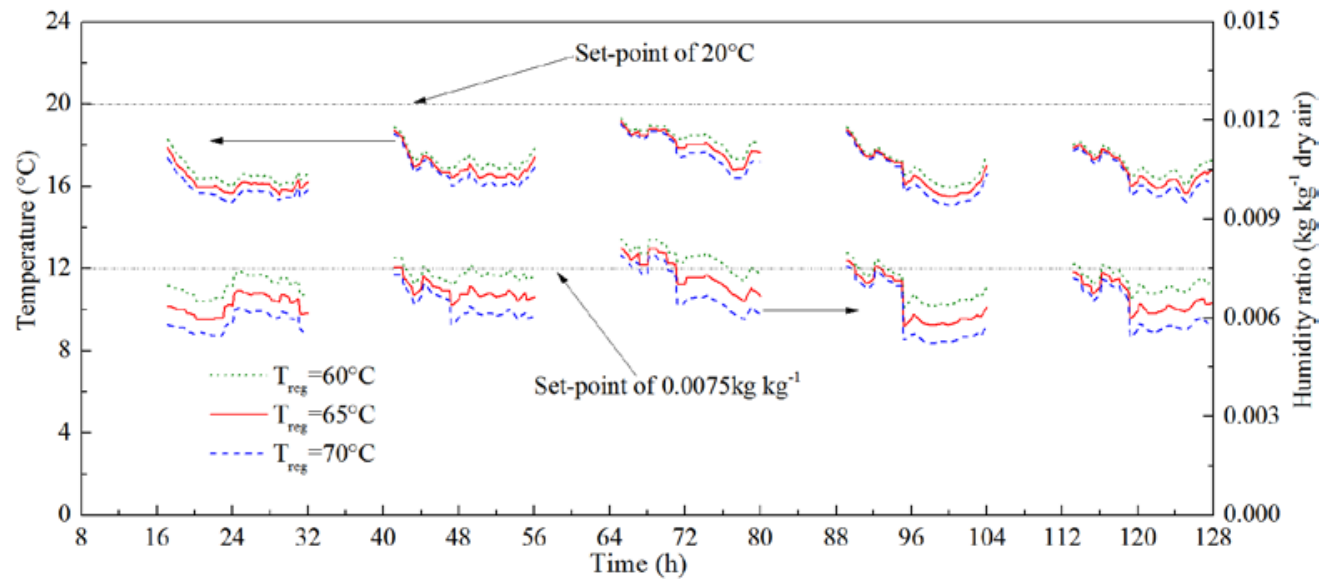

Fig. 11 Supply air conditions under different regeneration temperatures. 